Revista Iberoamericana, Vol. LXXV, Núm. 227, Abril-Junio 2009, 435-443

\title{
LA POSIBILIDAD DE LO IMPOSIBLE
}

\author{
POR \\ Paloma Vidal \\ Universidad Federal de São Paulo
}

I.

"Eu sempre sonho que uma coisa gera,/ nunca nada está morto./O que não parece vivo, aduba./O que parece estático, espera”. Estos versos de Adélia Prado son el epígrafe de O cego e a dançarina (1980), primer libro de João Gilberto Noll, ${ }^{1}$ y anuncian un tiempo de espera: ni de grandes esperanzas y aventuras, como el que afirmaba la subjetividad revolucionaria y vanguardista de décadas anteriores, ni tampoco el tiempo paralizado del horror y del miedo que se instauró a fines de los 60 en Brasil; un tiempo que no llega a ser nuevo, que espera, suspendido en la incertidumbre de la orfandad. Este es el tiempo de O cego e a dançarina, que se hace visible de manera ejemplar en su primer cuento, “Alguma coisa urgentemente”. La década se inaugura con una urgencia que se suspende por la imposibilidad de decir algo sobre el futuro, lo que no significa que no haya algo a esperar. La suspensión es indefinición, todo lo contrario de las certezas del fin que dominarían los discursos políticos e históricos de allí en adelante. En las próximas páginas, trataremos de los primeros libros del escritor brasileño para proponer una lectura de su obra que sigue el hilo de esa indeterminación abierta por su primer cuento.

Una especificación cronológica sitúa el inicio del relato en el período más duro de la dictadura brasileña: "No final de 1969 o meu pai foi preso no interior do Paraná. (Dizem que passava armas a um grupo não sei de que espécie)” (Romance e contos reunidos 684). En esa época el narrador era un niño. “Alguma coisa urgentemente” es un cuento sobre la muerte del padre, probable militante político, “filósofo sem livros, com uma única fortuna: o pensamento” (683). La decadencia de ese hombre colocará al niño frente a un futuro incierto, que deberá enfrentar con

\footnotetext{
1 João Gilberto Noll nació en Porto Alegre, en 1946. Sus novelas y cuentos han sido premiados innúmeras veces en Brasil, además de traducidos y estudiados en Inglaterra y en Estados Unidos. En 1997, la editorial Companhia das Letras publicó su obra reunida. Sus libros más recientes son Berkeley em Bellagio (2002), Lorde (2004, traducido al castellano y publicado por la editorial argentina Adriana Hidalgo, en 2006) y A máquina de ser (2006) y Acenos e afagos (2008).
} 
los instrumentos de una herencia precaria: ¿qué le deja el padre más que algunas imágenes dispersas de una causa que el hijo no llega a comprender del todo? Lo que el hijo ve es una extrema fragilidad donde se quiso mostrar fuerza, dureza y certidumbre. Este hombre que aparece y desaparece, cuya figura organiza entre ausencia y presencia el relato, y la vida del niño, es alguien inestable y solitario, abandonado en algún momento por su mujer con un niño a quien se siente en el deber de transmitir alguna enseñanza. "Ele me dizia que o mundo não era só aquelas plantas, era também as pessoas que passavam e as que ficavam e que cada um tem o seu drama [...] Ele me falava com o olhar visivelmente emocionado e contava que antes me ensinaria a ler e escrever" (683).

Pero el niño sabe mucho más de lo que el padre supone. La inocencia se ha perdido y ahora es el padre quien tendrá que aprender a "lidar com uma criança que sabe”. Se establece en el cuento una oposición entre saber y conocer: el niño tiene un saber que no se funda en el conocimiento de los hechos. "Eu me calava. Pois se referir ao meu pai presumia um conhecimento que eu não tinha” (684). El conocimiento quizás sea imposible frente a una realidad opaca, nebulosa, que resiste siempre en su núcleo real. El saber del hijo, podríamos decir con Lacan, modula “de una manera más radical esa relación del hombre con el mundo que durante mucho tiempo se tomó por el conocimiento" (74); este saber es precisamente la inocencia perdida y señala lo real que no se presenta como objeto cognoscible. Si el padre que debería transmitir el conocimiento es una figura desamparada, a merced de acontecimientos mayores, incontrolables, de una violencia extrema, el hijo sabe que deberá arreglárselas de otra manera, sin consignas, ni fundamentos, ni raíces.

"Alguma coisa urgentemente" se construye a partir de una desvinculación con el pasado que deja un vacío, un abismo, una pregunta sin respuesta. El relato no se circunscribe al destino del hijo de un militante político. Deliberadamente no se le ofrecen al lector detalles sobre acontecimientos históricos, no se le dice qué actividades ejercía ese padre o qué funciones cumplía, y sin embargo lo que se sabe es suficiente tanto para el narrador como para el lector; es suficiente para entender que frente a una realidad que se fragmenta y a un pasado que ya no sirve de lastre hace falta hacer "algo urgentemente”. La imprecisión del relato abre la lectura hacia un pathos generacional que, este sí, está muy bien explicitado, quizás como nunca en la literatura brasileña, como también estará presente en Caio Fernando Abreu, en el cuento “Os sobreviventes”, por ejemplo, de Morangos mofados (1982), que reúne los lugares comunes de una época enfrentada al agotamiento de las promesas de la modernidad: "Já li tudo cara, já tentei macrobiótica psicanálise drogas acupuntura suicídio ioga dança natação cooper astrologia patins marxismo candomblé boate gay ecologia, sobrou só esse nó no peito, agora faço o quê?” (27).

El padre va preso y el niño va a parar a un colegio interno. Cuando se reencuentran, el padre es un hombre envejecido, al que le falta un brazo, mientras 
que el niño ya es un muchacho. Viajan juntos a Río de Janeiro y el padre lo deja en un departamento en la Avenida Atlântica, en Copacabana, antes de partirnuevamente. La soledad y la espera dominan el relato. Recién en el próximo libro, A fúria do corpo, la intensidad de la calle se tornará irresistible y entonces el erotismo surgirá como vía sin retorno, como camino de perdición que le permitirá separarse de la herencia paterna y abandonarse al tránsito permanente.

Como veremos, la errancia es una marca fundamental de la narrativa de Noll y cabe plantearse qué significa ese constante movimiento sin recurrir, como frecuentemente se hizo, a la proyección de una flânerie moderna que fracasaría frente al individualismo posmoderno. Lo que inaugurará el personaje errante de $A$ fúria do corpo, este hombre "en estado de mendigo", según sus propias palabras, está lejos de ser apenas una actualización, dislocada e impasible, de la flânerie, una vez que se enfrenta abiertamente a una determinada moral de la contención, de la ascesis y del sacrificio, profanando con su sexo los espacios destinados a una sociabilidad controlada.

Surge así en la literatura brasileña un personaje diametralmente opuesto a la figura del héroe o del mártir o de cualquier otro ejemplar de una moral de la victimización y de la salvación. Escribiendo contra la ascesis, Bataille señalaba que en ella "el valor no puede ser únicamente la experiencia, independiente del placer o del sufrimiento, sino siempre una beatitud, una liberación que trabajamos para obtener" (L'expérience intérieure 34). Si la ascesis es un proyecto determinado por el "querer ser todo", podemos decir que el personaje que emerge en estas primeras narrativas de Noll se ha "desintoxicado", para usar otra expresión de Bataille, de ese deseo de totalidad, desintoxicación que, como también lo subrayó el escritor francés, no viene sin su carga de sufrimiento. Lo que encontramos es un personaje que "se mueve en un mundo extraño donde angustia y éxtasis se componen” (10).

"Alguma coisa urgentemente" se termina con el retorno del padre, que vuelve para morir al lado del hijo. "Eu vim para morrer [...] Vão te descobrir mas não dê uma única declaração, diga que não sabe de nada. O que é verdade” (686). Aparece de nuevo aquí la cuestión del saber y la suposición de una inocencia del hijo por parte del padre. Si, de un lado, el cuento relata, a través del desencuentro entre padre e hijo, un diálogo entrecortado entre dos generaciones, entre un conocimiento supuesto que se empieza a extinguir y un saber incierto que emerge en su lugar, la herencia del padre es una marca imborrable en la forma de una pregunta urgente, la misma del cuento de Abreu: ¿qué hacer? Una pregunta que no encuentra respuesta en el cuento y expresa toda la angustia del hijo frente a la acción necesaria, pero indeterminada. "Eu preciso fazer alguma coisa urgentemente, a minha cabeça martelava" (686). Ante el padre agonizante, el hijo sabe que ha llegado la hora de trazar su propio camino. El cuento se suspende en esa urgencia, cuando el hijo se 
enfrenta a los ojos duros del padre que antes de morir dice, por primera vez, su nombre, aunque para el lector el narrador permanece anónimo, como lo serán la mayoría de los personajes de la narrativa de Noll.

"Alguma coisa urgentemente" habla de los muchos significados de la pérdida, colocando en cuestión anticipadamente el significante que aparece con insistencia en las referencias a los años 80 . Recién empezada la década, el cuento lanza la pregunta provocadora: ¿qué se perdió? Vemos el padre perdido, muerto, y también su causa y la desorientación del hijo frente a la incógnita del futuro; vemos toda una épica revolucionaria perdida, pero la pérdida, aquí, como sugiere el epígrafe de Adélia Prado, abona, prepara el terreno para otro tiempo; la pérdida moviliza, pero tiene su tiempo propio, que no es el tiempo utópico, sino un tiempo que exige una inquietante suspensión de sentido. La indefinición del cuento, es decir, lo que el cuento deja intencionalmente indefinido, el futuro del hijo y el pasado del padre, anuncia un tiempo en que ya no existen lugares marcados, un tiempo que no cuenta con certezas redentoras y exige otra estética y otra política para atravesarlo. Leeremos en A fúria do corpo:

\begin{abstract}
sabemos de agora em diante que somos perdedores sim, mas exploraremos a devastação dessa derrota como quem garimpa na miséria riquezas indizíveis, não temos outro tesouro senão essa pobreza, tocamos a miséria da Cidade não para chafurdarmos prazerosamente no lodo da impotência mas para chegarmos até aqui, alçando nossa penúria, a nossa escassez, a nossa privação a inéditas rotas, vamos sim. (275)
\end{abstract}

II.

Derrotados, abandonados, huérfanos, estos son los personajes que definirán una estética y una ética de la precariedad en Noll, en el sentido de una carencia constitutiva y a su vez de una búsqueda de algo que está desde siempre perdido y que sin embargo se sigue persiguiendo, como para testimoniar una insistencia del deseo. En A fúria do corpo, nos encontramos con un lenguaje excesivo que deliberadamente choca con la precariedad para hacer transbordar los límites subjetivos. Los personajes son figuras despojadas de todo, marginales viviendo "nas raias do abandono", "sem um puto tostão na algibeira, sem cama, sem comida”(15). El lenguaje sin embargo se abre hacia el otro en una orgía verbal de repeticiones y frases que parecen no tener fin, una sintaxis desenfrenada en que el erotismo aflora sin pudor para tornar visible un encuentro entre esos cuerpos excedentes: "pego a mão de Afrodite, lhe digo é Carnaval, somos mais que amantes, irmãos vindos do mesmo plasma, o Universo uma grande placenta de onde saem todos, não há diferenças na forma, um pau uma buceta coisas assim” (184). Al protagonista de "Alguma coisa urgentemente”, suspendido en el vacío de la herencia paterna, $A$ 
fúria do corpo le ofrece peregrinar sin destino por las calles de Copacabana en pleno carnaval, meterse en sus callejones oscuros, exhibir una sexualidad ambivalente.

"Novela de acción” es como Silviano Santiago la nombra, advirtiendo que no se trata del "sentido tradicional del término", del bien contra el mal en las películas hollywoodenses. El cuerpo que se mueve con furia por la novela de Noll está lejos de ser el “cuerpo racional, musculoso y edificado” (Nas malhas da letra 72); es un cuerpo indigente y expuesto, cuyo erotismo a flor de piel atenta contra las instituciones, normas y disciplinas de una sociedad que, vale recordar, todavía se encuentra bajo el control de un Estado dictatorial. "Su brújula marca una única ruta”, nos dice Santiago, “un único desvío, pues se trata de desublimar el deseo que se reprimió detrás de las clases de danza y de natación, de gimnasia y de musculación, es decir, detrás de las actividades corporales hechas con reglas y asepsia” (73).

Para no dejarse “embalsamar num cidadão que desconheço”(9), el protagonista de A fúria do corpo no dirá su nombre. “Mi nombre no”, así empieza el relato de este vagabundo anónimo de las calles de Río de Janeiro, un ser sin historia, sin pertenencias, que cuenta con su cuerpo como única referencia: “só tenho o sexo e aqui estamos, e isso importa, estamos sentados um em frente ao outro em bancos do calçadão da Avenida Atlântica” (10). En una sociedad que nombra para controlar y subyugar, el personaje de Noll elige el anonimato, el margen de la ley y de las instituciones, tornándose un lumpen cuya subversión no está en ningún acto heroico, sino apenas en su existencia exterior al orden: "Não me pergunte pois idade, estado civil, local de nascimento, filiação, pegadas do passado, nada, passado não, nome também: não. Sexo, o meu sexo sim: o meu sexo está livre de qualquer ofensa, e é com ele-só-ele que abrirei caminho entre eu e tu, aqui” (9). En el anonimato quizás sea posible aproximarse a otro cuerpo, también sin nombre y sin historia: “não poderei vos doar portanto alegria mas só o anonimato mais vil se bem que anunciador de que alguma coisa cresce em mim, em nós, e nos toma, nos restitui ao esplendor mais humano” (12). La igualdad en el anonimato será una resistencia contra la jerarquía impuesta por un interlocutor que se supone superior y exige permanentemente que se sepa “con quién se está hablando”.

El erotismo de A fúria do corpo es, como afirmaba Bataille, un “desorden que perturba un estado de cuerpos que están conformes a la posesión de sí, a la posesión de la individualidad durable y afirmada” (17). Aquí todo se mezcla, se confunde, en la frontera abyecta que desequilibra al sujeto, que le hace encontrar sus límites y también le permite una apertura riesgosa hacia el otro. Dice el narrador: “eu mordia o seio que guardava o coração você me dizia vem, e em cada convite mais uma curva do labirinto se desenhava; eu enfrentava mais uma curva e me perdia mais uma vez ao teu encontro. E cada encontro nos lembrava que o único roteiro 
é o corpo. O corpo" (23). El efímero encuentro se da por el cuerpo, siguiendo sus marcas, su itinerario, sus desvíos: "Quando a gente se encontrava você dizia meu coração tá doendo, toca aqui. Eu tocava no coração com a mão espalmada sobre teu peito e sentia o coração responder: pulsava ali uma outra vida que não a minha, um outro ser vivo no mistério mas tão mineral que eu podia tocar” (23). A fúria do corpo muestra un cuerpo erotizado y desterrado, un ser vivo sin marcas de identidad o de nacionalidad que se abandona al cuerpo del otro. Es una novela sobre el amor, el exceso, la disolución del yo.

"Es una novela sobre la posibilidad de lo imposible", dice Noll, y en sus palabras oímos el eco de un debate del inicio de los 80, cuando se publican textos fundamentales sobre el tema de comunidad, como el de Jean-Luc Nancy, La communauté désoeuvrée, y el de Maurice Blanchot, La communauté inavouable, que releen la obra de Bataille para tratar de responder ciertas preguntas que siguen abiertas frente a los restos totalitarios del comunismo: ¿quésignifica una comunidad? ¿qué proyecto comunista, comunitario o comunal aún sería posible concebir? El epígrafe del texto de Blanchot es una formulación de Bataille que marca todo el pensamiento subsiguiente sobre la (im)posibilidad de comunidad: "La comunidad de los que no tienen comunidad”. La comunidad sólo se puede pensar como inacabada, en vías de deshacerse, "recusándose a hacer obra”, dice Nancy, "preservando así la esencia de una comunicación infinita” (39), de una "conversación infinita”, como proponía Blanchot, que gira necesariamente en torno a algo inconfesable y fundante, esa experiencia-límite ${ }^{2}$ que nos une y que la escritura deja en descubierto.

La narrativa de Noll transita entre la posibilidad y la imposibilidad de comunidad, sin jamás decidirse, mostrando un sujeto que ha perdido todo, que ha sido abandonado pero que no abandona su búsqueda, sino que a cada libro la reinicia. "Transformar en acción toda su negatividad”, decía Blanchot. Esa persistencia, esa insistencia en un mismo personaje que siempre retorna y una vez más emprende su errancia, esa marca de estilo, fue interpretada frecuentemente como un anuncio del fin del relato y de muchos otros fines. Sin embargo, lo que se ve parece ser lo contrario: la repetición de una misma escena de despojamiento que deja al sujeto disponible para lo que pueda suceder de imprevisible.

2 En un texto sobre la “experiencia interior" en Bataille, intitulado precisamente "La experiencia-límite”, Blanchot escribe que "al hombre, tal como es, tal como será, le pertenece una falta esencial”, a lo que añade en una nota: “¿Pertenece? Sí, es un pertenecer sin pertenencia; de nuevo una relación que se sustrae a sí misma” (305). Algo que se da y se sustrae, que se afirma y a la vez se niega, la superación de lo insuperable, la potencia impotente -en la paradoja se formula necesariamente este pensamiento que encuentra la comunidad fuera de toda comunidad. 
III.

En su tercera novela, Rastros do verão (1986), lo imprevisible aparece como una mirada ajena que cruza el camino del protagonista inesperadamente. La trama, como siempre, es mínima: un hombre anónimo, vagando sin destino por un Porto Alegre vacío en un martes de carnaval; sus acciones no parecen llevarlo a ningún lado, no tiene intenciones, objetivos, metas; al llegar, conoce un muchacho con quien va a deambular por la ciudad; luego conoce a la dueña del departamento donde vive el muchacho, va en busca de su padre en un hospital y por fin vuelve a dormir en la casa del muchacho. Como siempre la errancia y como siempre el encuentro inesperado:

Vou ficar na chuva, eu disse - aquelas coisas que costumava dizer quando estava muito só. Alguém sentado ao meu lado disse que faria o mesmo. Olhei para o lado e vi que era um garoto que deveria andar nos 17, no máximo nos 18 anos. Ele vestia uma camiseta e uma bermuda. Sim, a chuva, eu respondi. E aproveitei para perguntar como ele estava indo de carnaval. (327)

En lo que llamamos posmodernidad, cuyo pathos se delinea más claramente, sobre todo en Latinoamérica, en estos años en que Noll comienza a escribir, el "individualismo propulsor de la modernidad pierde su sentido heroico y crítico" (Moriconi 22-23). Si el sujeto moderno se sentía oprimido y de esa opresión erguía su deseo de autonomía para actuar y transformar la realidad, en la posmodernidad esa autonomía tiende al aislamiento. Pero en la narrativa de Noll, el sujeto aislado posmoderno está siempre atravesado por encuentros fugaces que lo descentralizan, breves aproximaciones que en los textos posteriores a A fúria do corpo serán de pocas palabras; ya no una comunión erótica verborrágica, sino un silencio mediado por el cuerpo. "A sua pele arrepiou-se, e numa eletricidade a minha mão também. Senti que podia ir. E entrei dentro dela” (Romance... 343), leemos en Rastros do verão. El cuerpo seguirá siendo el roteiro, ese "corpo cheio de fúria” (347) que reaparece aquí como el vestigio de un exceso ahora transformado en una "una inquietud, una pregunta sostenida por la posibilidad de formas de asociación duraderas que no respondan a los modelos habituales: familias imposibles, domesticidades infinitamente abiertas” (Laddaga 196-197).

La urgencia de comunicar lo incomunicable, de actuar cuando la acción es un gesto que se interrumpe, de formar comunidades imposibles, este es el límite en que transita la narrativa de Noll, cuya trayectoria propone una política que se puede denominar, con Agamben, de los medios puros, ${ }^{3}$ porque no se ubica en el

3 Podríamos denominarla también, con Bataille, “política de lo imposible”. Como propone Jean-Michel Besnier a respecto de este concepto: "Es precisamente el inacabamiento que significa en primer 
terreno de la finalidad, sino en el de una gestualidad en que "nada se produce o se actúa, sino que se soporta y se sustenta" (Means Without End 56). Vivimos en una confusión de cuerpos y lugares, de fuera y de dentro, de comunicable e incomunicable, de esclavitud y libertad, de necesidad y deseo, lo que implica una experiencia cotidiana de impotencia y soledad. Pero es desde ese terreno incierto, desde esa zona de indistinción, nos dice Agamben, que se puede encontrar el camino para otra política, otra palabra, otro cuerpo.

En un texto de 1990 sobre el tema de la comunidad, Agamben afirma que la debemos pensar a partir de la singularidad, es decir: de un ser que mantiene una relación original con el deseo y está abierto al otro, a la posibilidad de estar en el lugar del otro, expatriado como él; un ser, añade, que ya no busca una identidad propia en la individualidad, en una biografía particular, sino que adhiere a "una singularidad común y absolutamente expuesta” (La communauté... 67), un fuera de sí que es la única posibilidad de éxtasis en este mundo posmoderno al que llegamos con las manos vacías. Este tipo de comunidad que no reivindica una identidad, en que los seres pertenecen sin una condición de pertenencia representable, es lo que el Estado no puede soportar y transforma en su principal enemigo.

Asítermina el texto de Agamben, remitiéndonos a una división entre comunidad y Estado. La comunidad es el lugar de una singularidad irreducible, mientras que la ciudadanía conlleva la indiferenciación abstracta de los individuos, lo que concretamente significa, como insiste Agamben, ${ }^{4}$ una distinción entre las vidas que cuentan y las que no cuentan. A contrapelo de una lectura "posmoderna" de la narrativa de Noll, que ve en la errancia sin destino de sus personajes la ratificación de una existencia individualista en un mundo globalizado que celebra la disolución del Estado, pensamos la errancia como una apertura a lo imprevisible de esta existencia. Retomada en cada libro, la errancia, además de testimoniar el inacabamiento de la obra, sustenta la posibilidad de exceder los límites de la identidad y acceder a comunidades que opongan resistencia a un poder diseminado pero no por eso menos determinado a ejercer control sobre los cuerpos.

lugar lo imposible” (81). La política de lo imposible, afirma Bataille, es la vía para descubrir una política de lo posible sin dejarse aplastar por la parálisis y el conformismo. Se trata de ir al límite de lo posible, cultivando una resistencia sin proyecto, una "revuelta contra lo que se pretende acabado, pleno, transparente y necesario" (125).

4 Específicamente sobre el tema de la ciudadanía, Agamben observa que ya en la "Declaración de derechos del hombre y del ciudadano", de 1789, se establece una indistinción entre "hombre” y "ciudadano" que marca la inauguración de la biopolítica en la modernidad, puesto que el "hombre" es subsumido en la categoría política de "ciudadano" para que sus derechos sean preservados bajo la soberanía de la nación. Surge así una separación entre los derechos del hombre y los derechos del ciudadano. Desde su nacimiento (el término "nación” deriva etimológicamente de nascere, "nacer", observa Agamben), los sujetos son transformados en ciudadanos y lo que queda fuera de esa categoría es vida que puede ser sacrificada. Véase Agamben, Homo Sacer... 126-135. 


\section{BIBLIOGRAFÍA}

Abreu, Caio Fernando. Morangos mofados. Río de Janeiro: Agir, 2005.

Agamben, Giorgio. La communauté qui vient: théorie de la singularité quelconque. París: Seuil, 1990.

Means Without End. Minneapolis: U of Minnesota P, 2000.

Homo Sacer: Sovereign Power and Bare Life. Stanford: Stanford UP, 1998.

Bataille, Georges. O erotismo. Porto Alegre: L\&PM, 1987. L'expérience intérieure. París: Gallimard, 2006.

Besnier, Jean-Michel. La politique de l'impossible: l'intellectuel entre révolte et engagement. París: La Découverte, 1988.

Blanchot, Maurice. L'entrétien infini. París: Gallimard, 1995.

Lacan, Jacques. Les quatre concepts fondamentaux de la psychanalyse. París: Seuil, 1990.

Laddaga, Reinaldo. “Sobre Lorde, de João Gilberto Noll”. Grumo 5 (Buenos Aires, 2005): 196-97.

Moriconi, Ítalo. “Tentando captar o homem-ilha”. Matraga I/2-3 (mayo-diciembre, 1987): 21-29.

Nancy, Jean-Luc. La communauté affrontée. París: Galilée, 2001.

Noll, João Gilberto. A fúria do corpo. Río de Janeiro: Record, 1981.

Romance e contos reunidos. São Paulo: Companhia das Letras, 1997.

Santiago, Silviano. Nas malhas da letra. Río de Janeiro: Rocco, 2002. 
1 